\title{
From the Perspective of Musicians in Goa: How Has Tourism Changed Music Culture?
}

\author{
Ranjeeta Basu, Mtafiti Imara \\ California State University San Marcos, California, USA
}

\begin{abstract}
The objective of this paper is to assess the impact of tourism on the local music culture in Goa from the perspective of musicians. We consider musicians to be one of the principal, yet often understated agents of cultural change. Musicians are both economic and cultural actors. In the economic space, they participate in the labor market of the tourism industry by performing at local restaurants, hotels, cruises, and other tourist venues, and they make changes to their music in the cultural space by responding to tastes and preferences of tourists. This research is an interdisciplinary study of the nexus point among these overlapping spaces in order to understand how musicians have been affected by and have responded to tourism, which may in turn change the collective identity of the community. It is an exploration of relationships among cultural change, power, and identity. Our findings suggest that tourism in Goa has undoubtedly raised incomes of musicians but not necessarily their well-being. Tourism has also significantly changed music culture in Goa.
\end{abstract}

Keywords: interdisciplinarity, artifact, performance practice, aesthetics, spiritual significance, well-being, Goa

\section{Introduction}

This paper focuses on the relationship between tourism and music culture in Goa. Although the central government has promoted tourism in Goa since the 1970s, it was not until 2001 that the state government of Goa formally adopted the Goa Tourism Master Plan (Goa Department of Tourism, 2001), which focused on tourism as a primary factor in its development strategy. Many economists have argued that tourism can lead to long-term economic growth (i.e., tourism-led growth hypothesis), increased employment opportunities, and can be a significant source of foreign exchange revenues (Balaguer \& Cantavell-Jorda, 2002; Dritsakis, 2004; Fayissa, Nsiah, \& Tadasse, 2007; Oh, 2005). As a result, governments of many countries, as well as multilateral organizations such as the World Bank, International Monetary Fund, and the World Trade Organization (WTO), promote tourism as a development strategy for low-income countries. Conversely, other scholars and activists (Noronha, 1997; Saldanha, 2002; Swords \& Mize, 2008) are reserved in their advocacy and are much more critical of the impact of tourism. Their areas of concern include environmental degradation of tourist areas, rising real estate prices, social displacement of local communities, creation of primarily low-skilled jobs, exacerbation of social inequalities, lack of linkages with local economies, and the disruption and commoditization of local culture. They implicitly addressed the differentials in power that lead to these negative consequences. In aforementioned cases surveyed, tourists 
are from high-income countries and the tourist destinations are in low-income countries. Thus, the trade process occurs within the context of unequal power in the world economy. ${ }^{1}$ This paper contributes to this ongoing policy debate by focusing on the relationship between tourism and changes in music culture within the specific context of Goa. The uniqueness of Goa's social, political, and cultural history and the changing economic condition in India has resulted in a "context" that belies an assessment of global north (high-income) to global south (low-income) relationships as the only power differentials that matter. The complex of both domestic and foreign tourism confounds a heretofore traditional analysis (Urry, 1990) and begs the question of the relationship between agency and identity locally. This paper calls for an examination of power differentials within a country and the role that domestic tourists play in bringing about change in a tourist destination.

\section{Developing an Interdisciplinary Approach}

Culture in any society is always changing and adapting to changing conditions. We treat tourism as one factor in this cultural dynamism. According to Nkrumah (1970), change occurs as a result of a "plenum of forces in tension". Akin to this philosophy, we define interdisciplinarity as bringing together and utilizing primary assumptions, theories, and methodologies, derived from disparate branches of knowledge towards the end of addressing "real-world" problems. In our case, we include fundamental assumptions, theories, and methodologies from economics and music composition. Our challenge is to understand how a global economic force, such as tourism, plays out in a local context in the lives of musicians.

\section{Assumptions}

In order to help us understand and analyze the relationship between tourism and music culture, we selected these assumptions to serve as a starting point of our analysis:

(1) The individual musician is the primary unit of analysis. His/her creative process is affected by global economic forces such as tourism. At the same time, musicians have the agency to bring about cultural change;

(2) Tourism is both an economic and a cultural activity. Musicians, as agents of change, act and react to tourism within both the economic and cultural spaces;

(3) Cultural change can be assessed by observing and describing transformations and interrelationships among specific levels (or conceptual spaces) of cultural expression and production.

\section{Theories}

Several actors shape tourism as a global economic force. Tourism, as a form of trade, is promoted by multilateral agencies such as the WTO as a viable development strategy. Tourists are drawn to tourist destinations for a variety of reasons such as the natural beauty of the sites, historical/architectural uniqueness, music/dance culture, "way of life", and activities such as skiing, trekking, water sports, etc.. Accordingly, the tourism industry, in collaboration with local government agencies, packages and sells these tangible and intangible assets of the destination as a form of identity branding or product differentiation.

\footnotetext{
${ }^{1}$ BRIC (Brazil, Russia, India, and China) countries are confounding this paradigm.
} 
Let us consider Krugman's (1979) basic trade model, under conditions of monopolistic competition ${ }^{2}$ and increasing returns to scale ${ }^{3}$, as our starting point. According to this model, trade will lead to lower costs of production, lower prices, and a greater variety of products. By providing access to a bigger market, trade leads to increased economic activity, more jobs, and higher incomes. Using this model to analyze the impact of trade on cultural change, Caplan and Cowen (2004) predicted that trade should lead to greater "cultural diversity" defined as choice of differentiated products available to consumers. Krugman's model, however, also predicts that as countries start trading, there will be fewer varieties of products produced within each country. Applying Krugman's model, we can predict that although an expansion of tourism offers consumers more choices in the world market, within a particular destination country, tourism will cause certain forms of cultural expression to thrive, but will cause other forms to shrink and even disappear over time as they vie for space in the cultural marketplace. Tourism as an economic force, therefore, intensifies the commoditization of cultural expression, which implies a greater focus on exchange value versus use value (Attali, 1985). In this context, music is a form of cultural expression produced by musicians and consumed by tourists.

This interaction between tourists and local musicians is the focus of our study. Standard economic theory would predict that the tourist-host interaction is based on tourists and musicians maximizing their own utility. In other words, tourists make choices about which cultural product they will consume or which kind of music they will listen to based on their own tastes and preferences. Their choice(s) as well as their "gaze" (Urry, 1990) are often tempered by the desire for an exotic/novel experience ${ }^{4}$. The accumulation of consumption capital (Stigler \& Becker, 1977) refers to prior familiarity with and/or training in the forms of music available in the destination country. Stigler and Becker (1977) argued that the greater the exposure to a certain kind of music, the greater the consumption of that kind of music. Lack of prior familiarity, the absence of information about the quality of the music, and high transaction costs of obtaining information cause many tourists to either rely on tour operators/guides as mediators or reference music they already know and appreciate. While it is true that access to the internet and other information sources might have made it easier for some tourists to be better informed, the quantity and sheer scope of information do not necessarily imply that the information is reliable. On the other hand, tourists value listening to music they consider exotic/strange/unfamiliar. In fact, experiencing a culture that they have never interacted with might be what has drawn them to the tourist destination in the first place. In sum, tourists will maximize their experience by trying to balance the familiar with the unfamiliar. The tourism industry is well aware of this dilemma and they will try to meet the demands of different types of tourists by offering differentiated products while minimizing costs at the same time. Economic theory would argue that musicians who can produce music that coincides with the tastes and preferences of tourists will thrive and others will decline. According to standard theories of trade, increased tourism should lead to an increased demand for all workers in the tourism industry, including musicians, which in turn will lead to an increase in employment and wages of these workers. However, as mentioned before, a rise in tourism will cause some types of music to thrive while potentially causing others to decline. Musicians who can perform a wide range of musical styles and are able to adapt to changing tourist demands will tend to benefit economically from tourism compared to musicians who cannot or choose not to make those adjustments.

\footnotetext{
${ }^{2}$ A type of imperfect competition characterized by differentiated products, no barriers to entry, and large numbers of buyers and sellers.

${ }^{3}$ Refers to a production process wherein as the scale of production increases, average costs fall.

4 The use of this term here does not preclude or disavow "exoticism" that indexes hegemonic relationships articulated in various post-colonial discourses.
} 
This analysis is useful but incomplete. We would like to extend the economic analysis in some important ways. Economic theory is based on the assumption of the "economic man" who is rational and always takes actions to maximize his/her utility given the constraints of the market. Borrowing from the well-being literature $^{5}$ (Seligman, 2011; Sen, 1999), we would like to enrich the analysis by arguing that the well-being of individuals, in our case, musicians, is based not only on their ability to make a living, but it is also based on trying to maintain their own artistic integrity. Specifically, artistic integrity refers to the capacity to discern one's own aesthetic preferences and principles while exhibiting consistency within that aesthetic framework in the pursuit of creative endeavors. Ultimately, the measure of artistic integrity is akin to a measure of one's well-being, particularly with regard to meaning and accomplishment. This state of being whole, honest, and undivided in one's music is often challenged by the immediate need to make a living and the exigencies of the labor market for musicians. There are very few barriers to entry in this industry which means that not only do musicians compete with each other for gigs at local tourist destinations, but they do so under conditions that challenge collective and/or community artistic integrity. Musicians are faced with making very difficult choices about their music that balance their need for making a living on one hand, with their need for artistic integrity on the other hand. We posit that the individual choices they make have a profound cumulative effect on music culture in Goa.

Borrowing from post-colonial literature, we posit that the actions of both tourists and musicians are conditioned by broader narratives about the "other". Several scholars have discussed the power of the First World discourses to construct the Third World tourist destinations in order to perpetuate post-colonial representations of the other (Bandyopadhyay, 2009). In addition, the tourism industry and the state government in the host country also contribute to tourist perceptions of the destination (Bandyopadhyay \& Morais, 2005). The musician in this instance is not immune from the broader post-colonial narrative (Fanon, 1967). This conditioning affects their musical choices in relation to both international and domestic tourists.

Finally, borrowing from the music compositional process, we argue that beyond a consideration of the basic elements of music, i.e., rhythm, melody, harmony, timbre, and form, which when critically arranged make up the "stuff" of different musical genres and styles, is the concept of music culture. According to Cabral (1978, p. 223), culture can be defined broadly as "the dynamic synthesis of a people's experiential knowledge, beliefs, values, and norms that express and derive from the conflict at each stage of their development in the search for survival and progress”.

Accordingly, we analyze changes in music culture at four levels: artifacts, performance practices, aesthetics, and spiritual significance. This theory of cultural levels is a composite view taking into account that culture can be expressed as material objects, actions, ideas about what constitutes best practices, and meaning derived from the exigencies and challenges of life and its resultant identities. Although the notion of levels implies a movement from the concrete to the abstract, these levels are not mutually exclusive and in fact

\footnotetext{
${ }^{5}$ Sen (1999) introduced the idea that well-being is related to an expansion of “capabilities". The ability to get an education, to have access to drinking water, healthcare, safe working conditions, or to be free of harassment might be examples of activities or "functionings" that we might value as a community. An individual's "capabilities" are "the alternative combinations of functionings that are feasible for her to achieve” (Sen, 1999, p. 75). Seligman (2011) developed a dashboard approach to well-being called PERMA, which combines objective and subjective measures of well-being. This acronym stands for positive emotion, engagement, relationships, meaning, and accomplishment. He believed that as human beings, all of these factors affect our well-being. Experiencing positive emotions on a daily basis is important, but it needs to be balanced with a sense of purpose and achievement. According to Seligman (2011), we need to feel engaged with our community, with each other, and with our jobs to improve our well-being.
} 
overlap both causally and descriptively. Changes at the artifact level include changes in the use of specific instruments, number of instruments used, type/form of instruments, and derivative technologies. For example, the use of the tabla box and tanpura box ${ }^{6}$ in Indian classical music and/or the use of other digital forms of music, such as pre-mixed tracks and samples being used in "live" performances, are artifactual changes made in part, in response to economic pressures.

Changes at the performance practice level may include changes in the length of each piece, venue, choice of genres (esp. various types of fusion) repertoire shifts, language, and the manner in which instruments are played. Firms in the tourism industry tend to vacillate among these extremes, because they want to differentiate the product they offer tourists so that it is perceived to be unique and/or authentic. At the same time, they also want it to be familiar enough with performance practices that tourists are accustomed in order to meet tourists' preferences. In other words, performance practices are now being determined less by their traditional function and more by the commercial needs of the tourist industry. For example, changes made to length and form of a traditional folk performance when it moves from the village to the stage. Changes at the aesthetic level include changes in artistic standards, expectations of the audience/artist with respect to different art forms. Educational, religious, and other community institutions, as well as individual innovators, have traditionally determined these standards. Tourism has become another factor in this equation contesting the control of cultural space. For example, the degree of accommodation by presenters and musicians to tastes and preferences of tourists (foreign and/or domestic) could ultimately challenge the aesthetic sensibilities of the host community in determining artistic standards. In addition to having a sanctioned convergence of cultures, a potential intersection of the "one" and the "other", state-sponsored tourism sets up conditions for cultural accommodation-a musician must now choose between being an artist with an aesthetic imperative derived from a local community and being a craftsman "with manual, non-intellectual, repetitive, and unimaginative dexterity” that facilitates global-homogenized forms (King, 1999, p. 34). This may seem to be a small matter, or a benign adjustment, if one focuses on the individual musician. But when taken collectively, as a community of musicians who make similar adjustments in their performance practices and aesthetics, this can become a measure of, if not also "herald”, fundamental changes in music culture (Attali, 1985). Changes in the level of spiritual significance include changes in meaning derived from particular music practices, the underlying philosophy and/or belief systems, and ultimately collective and/or individual identity. For example, when a musical practice shifts from a traditional community setting to a tourist venue, the principal function of that practice often changes, resulting in a shift in the spiritual significance of that practice. Tourism can also challenge identity by arbitrarily collectivizing a set of characteristics and positing it as the identity of the host community. For example, the tourism industry in Goa packages an essentialist narrative as to what constitutes Goan-ness in order to sell it to tourists. Tourists form a notion of what constitutes Goan-ness in part influenced by this narrative. Therefore, when local Goans interact with tourists, they have to contend with this largely arbitrary, manufactured image of themselves, i.e., a challenge to their own identity. Historically, most scholars have looked at these areas or levels as separate and unrelated. De-contextualization, compartmentalization, and cultural fragmentation may occur when we do not consider the interrelatedness of all the four levels discussed above. Musical practice stripped of its context results in change of significance, change in identity, and subsequent changes in social political relationships. This is particularly the case in ethnographies drafted by

${ }^{6}$ These are digital, electronic devices, which substitute for a live accompanist performing with a sitarist or a vocalist. 
westerners about non-westerners; historically, the colonizers have described the colonized. But much post-colonial theory has sought to re-examine the terminology, as well as methodology that has characterized the world in terms of the "one" and the "other" (Said, 1979; Bhabha, 1990).

\section{Methodology}

One challenge of this project was to develop an interdisciplinary methodology appropriate to our research question. Another methodological challenge from a social science perspective was an absence of published macro-level data on musicians in Goa given that musicians work largely in the informal sector. We chose not to use purely discipline-specific approaches from ethnomusicology (ethnographies) or economics (drawing inferences about the population from data collected via sample surveys). Instead, we combined the two approaches and conducted 48 in-depth interviews and several performance observations. We took testimonies from musicians, music producers, owners/managers of tourist venues, event organizers, owners of music shops, music educators, as well as prominent authors and social/cultural commentators. The interviews included both quantitative and qualitative items aimed at eliciting information about the musicians and the conditions under which they made choices about their musical expression at each of the aforementioned four levels. For this paper, we focus on musicians we interviewed during the first phase of this project. Most of the musicians in our sample for this phase of the project are male, Catholic, and residents of the coastal talukas/districts of Tiswadi, Salcette, Bardez, and Mormugao. The impact of tourism is the strongest in these districts. The genres represented by this sample include mando ${ }^{7}$, tiatr $^{8}$, fado $^{9}$, jazz, western art music, pop/rock, and to a much lesser extent, Hindustani classical music. Most of the musicians we interviewed performed western derived music.

\section{Historical Background}

Goa offers a complex "field of action”" ${ }^{\prime 10}$ for which to study the processes of how music culture can change, in general, as well as how it can be altered by tourism, in particular. It is a rich social milieu because of its unique political history, ongoing experience with global economic forces, and a musical heritage derived from centuries of synthesizing a range of cultural and religious influences. Goan author, Maria Couto, viewed "globalization" as a historical fact in Goa that precedes the contemporary definitions and situating of the term. Goa has experienced several waves of "globalization” throughout its history. This history includes invasions and occupations (Moghul/Islamic), colonization (Portuguese/Christian), and most recently, annexation by India. Goa was a Portuguese colony for over 450 years and the centerpiece of Estado da India. During this time, the Portuguese had a profound impact on every aspect of Goan culture. This is especially the case in Tiswadi, Mormugao, Salcette, and Bardez—the coastal districts that constitute the Velhas Conquistas (Old Conquests).

\footnotetext{
${ }^{7}$ Mando is a musical form that developed among Goan Catholics during the 19th century. According to Phaldesai (2004), it is a blend of Indian and Portuguese traditions. Mandos were love songs that were typically performed at weddings and other family/community celebrations.

${ }^{8}$ The tiatr started in the Goan community in Bombay in the late 1890s. It is a very popular genre that reflects grassroots sentiments and includes oral and literate traditions (primarily in Konkani). Typically, each production runs for 100 shows at three hours each. These productions are very labor intensive and require 30-40 rehearsals per production. The economic sustainability of the tiatr is in jeopardy due to historically low ticket prices and minimal institutional support.

${ }^{9}$ Fado is a musical genre from Portugal based on themes of longing and loss. Amalia Rodrigues is one of its most famous exponents.

${ }^{10}$ This notion suggests that a community not only be studied from a narrow range of academic perspectives, but "the dynamics and relationships that characterize its cultural and social development” may necessitate interdisciplinary approaches (Hamilton, 1988, p. 23).
} 
Couto (2004) argued that this area represents one of at least two constructions of Goa. He called it Goa Dourada. In this area, there is a very strong Christian influence. The Hindu musical traditions are dominant in the other seven talukas ${ }^{11}$ or Novas Conquistas. Couto referred to these latter areas as Goa Indica.

The Jesuit presence in Goa, coincident with early Portuguese colonization, ensured that western music education was a mandatory part of the curriculum in the parochial schools. In addition to musical training offered by the mestre (choir director) at local churches, music was also integral to catechism and subsequent acculturation processes. As a result, Goa became the principal training ground for western music in India. According to Gerson da Cunha (1894, p. 186), “The greatest benefit that has accrued from these primary schools to the Indians who have frequented them from the beginning of the 16th century to the present is the cultivation of music". Even though most Goan folk traditions pre-date the Portuguese occupation (Phaldesai, 2004), these traditions are prominent in the Novas Conquistas. According to the Principal of Goa College of Music, Dr. Kamlakar Naik, the Portuguese did little to support, and in fact, established barriers to Hindustani classical and Carnatic (south) music. Prospective students had to leave Goa and go to other parts of India in search of good teachers. Artists from greater India could not enter Goa without visas, thereby minimizing the interaction with Goans. After 1962, when Goa became a part of India, this emphasis on western classical music changed. The government set up schools and universities, such as the Kala Academy and Goa College of Music that support a broader, more inclusive range of music education. Their express purpose is to celebrate diversity and promote unity in all aspects of Goan culture. ${ }^{12}$ In addition to western influenced art music (i.e., "classical” and "jazz"), there are other genres such as western pop, fado, rave/trance, Bollywood, and Goan folk music in the Konkani language such as the mando and the tiatr that continue to vie for cultural space.

Currently, the total population in Goa is 1.35 million, out of which $26.7 \%$ are Christians, $65.8 \%$ are Hindus, and 6.8\% are Muslims (Couto, 2004). This is a reversal of the trend during the Portuguese presence when there was a significant Christian majority in Goa. The growth of tourism and mining has created a huge demand for low-skilled labor which has been met by migrant labor from neighboring states. In 2008, in-migrants, primarily from the neighboring states of Maharashtra and Karnataka, constituted more than 20\% of the total population (Raikar, 2008). Bailey (2011) referred to this phenomenon as the "third Goa", the Goa of migrants. These facts, coupled with the ongoing out-migration and emigration of Goans, mark a definite shift in both demographics and cultural identity in Goa.

\section{Findings: Revisiting the Cultural Levels}

Currently, the economic picture for Goa is very promising. In 2007, Goa had the highest state per capita income (Rs. 30,000) in India with a high literacy rate (82.32\%). The Gross State Domestic Product registered an annual compound growth rate of $10 \%$ with the major contributors being tourism and mining (Kamat, 2007). According to the Goa Department of Tourism, 2.6 million tourists (more than double the number in 2004) visited Goa in 2011. One noteworthy trend is the growing percentage share of domestic tourists from $77 \%$ in 2000 to $84 \%$ in 2011 . According to a study done in 2005, the average tourist in Goa is male, well-educated, belongs to middle- to high-income groups, and comes to Goa primarily for leisure.

\footnotetext{
11 The Novas Conquistas consist of seven talukas: Bicholim, Canacona, Pernem, Ponda, Quepem, Sanguem, and Satari.

12 According to the Government of Goa, Directorate of Art and Culture website, the Kala Academy was set up to "promote the cultural distinctness/identity of this state”. Retrieved from http://www.artandculture.goa.gov.in/content_disp.php\#kala.
} 
According to Goa Department of Tourism's promotion videos and the tourism promotion materials available on the Goa Tourism Development Corporation's (GTDC) website ${ }^{13}$, a trip to Goa is represented as "a balm on the busy mind, to enjoy days of freedom on Goa’s magnificent beaches” and a place to "have fun”. Even though there are other types of tourism/tourists, Goa is clearly being marketed as hedonic tourism or pleasure tourism typically based on sun, sand, sea, and sex (Swarbrooke \& Horner, 1999). One local disdainfully referred to this packaging as "booze and beaches". This packaging is supported by the fact that the drinking age in Goa is lower than elsewhere in India. Bandyopadhyay (2010) used critical textual and visual analysis to conclude that western tourists view Goa as a hedonistic destination where "anything goes”. Live music is often an integral part of the party experience promoted by the tourism industry, so most restaurants and hotels that serve tourists hire local bands on a regular basis. Indeed, tourist venues are the chief sources of income and location to work. As a result, compensation and employment opportunities for musicians have increased with the increase in tourism. Demand for musicians is seasonal, although there are some domestic tourists who visit during off-seasons. Therefore, musicians are increasingly able to make a living from music, but it is an unstable source of income subject to the ups and downs of the tourist trade. ${ }^{14}$ Many of our interviewees are professional musicians who also hold other jobs in order to make a living but most wanted to work more hours as a musician. In what follows, we will combine direct testimonies and stories about a few of the musicians we interviewed with our own analysis of how their testimonies connect to the broader theoretical framework we discussed earlier.

Here is the story of one of the musicians we interviewed: Orlando de Noronha started playing at the age of four. His father used to play the violin and got Orlando started on the violin but he soon moved to the mandolin, Spanish guitar, and then Portuguese guitar. He started playing professionally at the age of 17 . He focuses on Goan, Portuguese, Latin, and jazz music, but music does not pay him enough to be a full-time musician. He performs only during the season when there are foreign tourists. The rest of the year there are "Indian tourists who don't listen to my music”, so he does not perform. According to Orlando, the hotels have a fixed rate and they offer the same rate to everyone regardless of quality. There are no unions for musicians so if someone is willing to play for less, then the hotels hire them. As a result, many good musicians are driven out. Orlando has been playing at the same hotels for many years. The audience will ask for songs (Hotel California is very much in demand) that do not sound good with the instruments Orlando has in his band but they "make it work". They do not play it like the original but play it in their own way. The hotel will not force them to sing songs the band do not like doing but Orlando rarely refuses a request. Orlando sees it as his job to satisfy the audience. They play music from 40 different countries. Most international tourists come from England and like music by the Beatles and Simon and Garfunkel. Orlando would like to play Bossa Nova, Latin, fado, or other forms of Portuguese music, but most tourists do not like that kind of music so he does not get a chance to play the music he enjoys. Orlando says, "When I am 40, I want to be a full-time musician and do what I actually love to do which is arranging and composing my kind of music". Orlando proudly claims that he is Goan first and Indian second. When asked whether tourism has impacted Goan identity, he said that, "Tourists like Goan culture, because it is unique and so they stay back here but then as many of them come here, the culture itself changes and it is no longer Goan". He argued that, "Politicians need to be kicked out, because they are the ones who are selling Goa to non-Goans”. According to Orlando, “Under the Portuguese, it was very safe but now the

\footnotetext{
13 Retrieved from http://www.goa-tourism.com/.

${ }^{14}$ For example, right after the terrorist attacks in Mumbai on November 26, 2008, there was a sudden drop in tourism, which caused many restaurants and hotels to cut back on the number of musicians they hire during the season.
} 
crime rate has increased because of the migrants. The politicians are encouraging the non-Goans to come here and they need to stop. We didn't have water and electricity for several days and therefore Goans leave, because they are fed up with all these problems. Instead of improving, things have become worse”.

According to Orlando's testimony, supported by other musicians, the managers of most tourist venues do not care about the quality of the music, a charge that was denied by the managers themselves. Both sides agreed, however, that managers make choices about which kind of music to promote based on what they can sell at the lowest cost to make the maximum profit. The managers will try to meet the demands of different types of tourists by offering differentiated products while minimizing costs at the same time. Accordingly, hotels have set compensation rates based on the number of musicians in the band. Thus at the artifact level, many bands are forced to compete by using recorded music tracks thereby reducing the number of musicians they have to pay. Vocalists have experienced an increase in demand, whereas other musicians have experienced a decline in demand (e.g., saxophonists, pianists). There is a diminished use of acoustic instruments in contemporary Goan music generally, in favor of computerized/electronic formats, perhaps reflecting global trends in this direction. In the long run, this change at the artifact level, i.e., shift away from acoustic instruments, could lead to a change at the aesthetic level as evidenced by a decline in well-trained exponents of these instruments. For example, while brass bands have traditionally been preferred for the traditional tiatr, lack of training and access (as well as demand) has resulted in fewer "blowing" musicians ${ }^{15}$. These results support the predictions from trade theory that some forms will thrive while others will disappear. But going further, these results also suggest that quality has been sacrificed in favor of profits.

The tastes and preferences of tourists play a significant role in determining the choice of music played at most tourist locations. According to the musicians we interviewed, many tourists in Goa want to listen to music that they are familiar with rather than listening to traditional Goan music. This is, perhaps, an indication that the music was not the principal attraction to Goa in the first place. Many domestic tourists typically request (and often demand) Hindi film music. International tourists typically prefer nostalgic western pop music. Some international tourists like to listen to Portuguese music such as the fado, which has had a resurgent popularity. Another small, but expanding group of international tourists and community of western expatriates like to listen to jazz ${ }^{16}$ in venues such as The Sol, Carvala, and Poco Loco. Local Goans typically like to listen to music sung in Konkani, a language spoken across the different ethnic/religious communities. Musicians who perform at hotels noted that the pressure to satisfy tourist requests is much stronger at hotels than at concerts or restaurants. Aesthetic sensibilities of tourists in this context challenge, if not also determine the selection of songs. If the musicians do not know the songs, then they make efforts to learn the songs in subsequent performances, regardless of the language, so that they can ultimately fulfill requests. Some of the musicians we spoke to such as the Cotta Family, who sing in 10 different languages, expand and develop their repertoire accordingly. Jazz pianist, George Fernandes, says that he “doesn’t play too heavy” but restricts the selection to "easy listening” jazz pieces. His focus is on the customer's taste. He takes some requests, but this accommodation is also limited by the skills/knowledge of other band members. According to the Goa Department of Tourism, a majority of the international tourists are from Russia (increased from $13 \%$ in 2010 to $30 \%$ in 2011) and the UK (decreased from 35\% in 2010 to 26\% in 2011), and a smaller number from the US,

\footnotetext{
15 That is, musicians who play wind instruments (trumpet, saxophone, flute, etc.).

${ }^{16}$ In recent years, the Heritage Jazz Foundation, headed by Armando Gonsalves, has produced an increasing number of programs featuring international jazz artists.
} 
Germany, Spain, Portugal, France, and Israel. Orlando stated that 10-15 years ago, (foreign) tourists would often request Strauss waltzes or tangos, but now they mostly request nostalgic rock music. For example, we saw an Elvis Presley impersonator in Calangute, at the Infanteria Restaurant, replete with a ten-gallon hat and an extensive repertoire of Elvis and Beatles tunes, all at three minutes each (even though the singer did not speak in English).

Several questions emerge from these findings at the performance practice and aesthetic levels that require further discussion. Firstly, why do tourists expect that Goan musicians will be able and willing to perform music that is outside of their cultural purview? Tourists regularly make requests of Goan musicians that are particular to their own culture/language. It is highly unlikely that German tourists visiting New Orleans will request a musician to play a German tune or Russian tourists visiting San Diego will request musicians to play a Russian song. Yet, tourists frequently make such requests when they come to Goa. Perhaps tourist behavior in Goa is a reflection of the larger hegemonic relationship between the West and the Global South. Or perhaps the expectation that the local Goan will accommodate tourists' demands versus the tourist adjusting to Goan culture is conditioned by Goa's reputation for being a place where "anything goes". Tourism has often been represented as freedom from everyday life and license to engage in behaviors that challenge social norms (Urry, 1990). In that context, tourist locations are viewed by the tourist as being devoid of problems, power differentials, and historical exploitation (Ateljevic \& Doorne, 2002).

The second question that our findings raise is why Goan musicians go to great lengths to accommodate tourist requests that are outside of their own language and/or local genres. The answer might lie in the fact that the Portuguese colonization of Goa is one of the longest in human history: 1510-1961. It was longer than all other Portuguese conquests, including that of Brazil, Mozambique, and Angola. Perhaps there is a deeper inculcation of Portuguese cultural influence, even given the sustained existence of groups of people who lived in Goa before and after the Portuguese arrival and departure. Some of our informants suggested that one resultant of this historical relationship might be a deep-seated disposition of inferiority vis-à-vis the Portuguese in particular and white Europeans in general, which may underscore broader Indian attitudes regarding race, color, and caste. This disposition of inferiority might make Goan musicians more likely to accommodate tourist requests. Another related reason why Goan musicians accommodate tourist requests might be the dispositional phenomenon of sossegado, alternatively described as quiet, calm, peaceful, or "laid-back". This "non-interfering" characteristic is the oft-cited reason for avoidance of conflict. In terms of a broader Goan music culture, there is an apparent inconsistency between the often-professed pride in Goan musical ingenuity and the practice of accommodation. If the integrity of an artist is, in part, measured by his/her commitment to his/her own vision, then gratuitous compromise may skew that vision and make the individual artist quite malleable in the hands of commercial interests, decidedly "non-musical variables". Musical flexibility is an admirable skill. It is a process of creative liminality whereby the artist balances the anxiety of exceeding his/her capacity with the challenge of learning new material (Csikszentmihalyi, 1990). However, the tendency to be self-deprecating or apologetic about playing their own/original music sets up an identity paradox.

Interestingly enough, the propensity towards accommodation does not extend to requests and demands made by domestic tourists. We found that Goan musicians, more often than not, accommodate requests of international tourists instead of domestic tourists. As mentioned above, there has been a growing number of Indian (or domestic) tourists who visit Goa, resulting from the rapid economic growth and rising incomes that many middle-class people in India have experienced. As a result, there is an increased demand for Hindi film 
music, as previously stated. Goan musicians seem very reluctant to accommodate requests from domestic tourists, especially requests for Bollywood music. The reluctance that many Goan musicians have to performing Bollywood music is ironic given that historically, Goans have played a prominent role in the development of Bollywood music (Fernandes, 2012). This aversion could arguably be a form of resistance towards the omnipresence and dominance of Bollywood music within India. But this resistance is clearly not directed towards the dominance of western music as discussed above. This is particularly ironic given that Bollywood music itself is influenced by western music. Perhaps this differential reflects the ethnic hierarchy established by the Portuguese over the course of 450 years of occupation, whereby the Goan Catholic was placed in a lower social stratum than the white Portuguese but a higher social stratum than the Goan Hindu and by extension Hindus from the rest of India. This internalization of an imposed social stratification might be another explanation for why Goan musicians willingly defer to requests made by western tourists but are far more reluctant to accommodate requests made by tourists from the rest of India. A third explanation might lie in the aesthetic sensibility of Goan Catholics which is far more conditioned by western inspired music than by Indian derived music with the caveat that these categories themselves are fluid and are subject to change.

According to Chhote Rehmat Khan, a sitarist and teacher at the Kala Academy, young musicians nowadays are less likely to pursue Hindustani classical music. Classical music (both Hindustani and western) requires many years of training but does not promise or foster hope that one can make a living from it. ${ }^{17}$ Given the increase in demand driven by tourism for other forms of music (such as rock, hip hop, and jazz fusion), many young Goan musicians are pursuing the latter forms of music instead of classical music. According to the cellist, Vasco Dias, there is some demand for light classical music played by chamber groups at some tourist venues, but that has declined since 2008. Most of the time, performances are in the form of concerts sponsored by institutions like the Fundação Oriente and/or Kala Academy. Most classical musicians who want to make a living from music (in Goa) turn to teaching, because most cannot make a living solely from performances alone. According to Khan, the demand for music teachers is also very low, because music is not mandatory in (elementary and high) schools as it was pre-1962, and there are only a few positions that might become available at the college level. Khan recollected how his father was "invited" to introduce the sitar to Goa from the neighboring state of Karnataka around 1978. Although he and other musicians in his family have tried to preserve and grow this tradition ${ }^{18}$, he feels that very few students are committed. They, and many of their parents, see this as a "hobby". He articulates globalization as "more of mechanical life" and states that, "Technically, we are growing more advanced [but] musically we are going backward". He echoes his grandfather when he states, "This music is not for entertainment, but for self-gratification”, and paradoxically, "Ragas cannot be taught, but they can be learned". For example, Khan noted that there is a movement away from playing ragas at strict prescribed times. ${ }^{19}$ Whether this is another consequence of globalization and/or modernization remains to be seen. It does, however, signal a shift in both aesthetics and spiritual significance. If musicians want to perform this music, they will be constantly challenged to negotiate between the knowledge and practices of their gharana ${ }^{20}$ and the exigencies of modern life.

\footnotetext{
17 No doubt a lament echoed by music educators globally.

${ }^{18}$ In addition to performing throughout Goa as a soloist and with family members, Mr. Rehmat currently teaches over 20 students at the Kala Academy in Panjim.

19 Sarokalaptas are a collection of ragas that can be played any time of the day, as opposed to traditionally prescribed.

20 Schools of sitar/performance associated with different places in India.
} 
When asked about identity, Orlando Noronha, and indeed most of our interviewees, said that being Goan came first and being Indian came second. Many felt that Goan identity is unique because of the Portuguese influence on food, dress, music, and dance, as well as the Portuguese language, which makes Goans different from the rest of India. All of them believed and stated that music was "in their blood". Although a decidedly essentialist notion, music is a significant self-identifier for Goans. When juxtaposed with international tourists, domestic tourists, or some "other" non-Goans, this facet of Goan identity becomes paramount. According to Vasco Dias, “As a child, I didn’t have exposure to other parts of India except for Bombay. But as a musician, I have travelled to Japan and elsewhere. When we were there, we would sing Goan music for them and they appreciated it and it made us feel that the music was very much part of our identity". According to Maria Couto, Goan identity is unique because of Konkani, the system of local self-government, and common property in the villages. The rich tradition of festivals, mother earth worship, and rituals that are part of Goan life in the villages is also at the heart of Goan identity. In our discussion with the musicians, they agreed that Goan identity is being challenged and concurred that tourism has played and continues to play a big role in this process of identity re-formation, but they had different perspectives on the extent and nature of the challenge. Tourism has created a demand for migrant labor, which has changed the mix and proportion of Goans to non-Goans in Goa. This is part of a longer historical process of emigration and out-migration by many Goans and in-migration by many non-Goans as mentioned earlier. Musicians such as Franz Schubert Cotta and Orlando Noronha had a very negative reaction to the rising presence of migrant labor, arguing that this has led to increased crime and vagrancy (a very common perception of migrants based on fear of outsiders and loss of homogeneity). They argued that Goa is being "sold" to outsiders by local politicians in order to make profits. Mario Miranda ${ }^{21}$, a prominent cartoonist and commentator from Goa, was nostalgic about the past and mourned the loss of the "Portuguese-ness" of Goan identity. He argued that Goans are losing their uniqueness and are "becoming like the rest of India". These views reflect a disposition and alignment of many Goan Catholics with Portuguese culture and history, and more broadly western identity resulting from 450 years of deliberate inculcation of this identity by the Portuguese. Thus, the growing presence of domestic tourists (as opposed to international tourists) presents a greater challenge to this manifestation of Goan identity. In other words, the Goa Dourada construction of Goan identity is increasingly challenged by the growing presence of domestic tourists and the growing presence of domestic labor from other parts of India.

However, not all the musicians we interviewed had the same viewpoint. There are some alternative views such as that expressed by rising fado singer Sonia Shirsat. Sonia did not receive any training in western music, because she grew up in one of the Hindu dominated talukas where it was hard to find teachers of western music. But her family is very supportive of her music. With a father who is Hindu and a mother who is Christian, Sonia represents both aspects of Goan identity. She asserts that the changing mix of Goans to non-Goans is reflective of an ongoing transformation of Goa into a cosmopolitan region with a rich, diverse blend of cultures. According to Sonia, Goan identity has always been about adjusting and accepting different cultures. Therefore, she sees the current negative reaction towards non-Goans as a temporary phase as Goans adjust to these changes.

${ }^{21}$ Mario Miranda passed away on December 11, 2011 prior to the completion of this research project. 


\section{Conclusion}

In conclusion, our study not only has provided some answers to the questions we started with but has also raised new questions that require further research. Tourism in Goa has undoubtedly raised incomes of musicians, but it has also fundamentally changed music culture in Goa. A rise in tourism has caused some types of music to thrive while causing others to decline. Musicians who can perform a wide range of musical styles and are able to adapt to changing tourist demands tend to benefit economically from tourism compared to musicians who cannot or choose not to make those adjustments. The choices they have made have a cumulative effect on music culture in Goa. In terms of policy directions, it is clear that institutions like the Kala Academy provide a very important counter-balance to the impact of tourism on music culture. The Kala Academy has played a role in preserving the living experiences of traditional performers and artists in a way that gives performers more cultural determination and autonomy, thereby increasing their capabilities and hence their well-being (Sen, 1999). The Kala Academy also plays a role in providing musical training to younger generations of musicians as well as preserving some levels of traditional local/Goan music culture.

\section{References}

Ateljevic, I., \& Doorne, S. (2002). Representing New Zealand: Tourism imagery and ideology. Annals of Tourism Research, 29(3), 648-667.

Attali, J. (1985). Noise: The political economy of music. Minneapolis: University of Minnesota Press.

Bailey, A. (2011). In search of livelihoods: Migration and mobility from Karnataka to Goa. In S. Rajan Irudaya (Ed.), Migration, identity, and conflict: India migration report 2011 (pp. 108-124). New Delhi: Routledge.

Balaguer, J., \& Cantavell-Jorda, M. (2002). Tourism as a long-run growth factor: The Spanish case. Applied Economics, 34(7), 877-884.

Bandyopadhyay, R. (2009). The perennial western images of India that refuse to die. Tourism: An International Interdisciplinary Journal, 57(1), 23-36.

Bandyopadhyay, R. (2010). You can do anything in Goa, India: Tourism as neocolonialism. In P. Burns, A. Lester, \& L. Bibbings (Eds.), Tourism and visual culture: Methods and cases (pp. 200-207). London: CAB International.

Bandyopadhyay, R., \& Morais, D. (2005). Representative dissonance: India’s self and western image. Annals of Tourism Research, 32(4), 1006-1021.

Bhabha, H. (1990). Nation and narration. London: Routledge.

Cabral, A. (1978). Obras Escolhidas de Amílcar Cabral: A Arma da Teoría. Unidade e Luta (Vol. 1). Lisboa: Seara Nova.

Caplan, B., \& Cowen, T. (2004). Do we underestimate the benefits of cultural competition? American Economic Review, 94(2), 402-407.

Couto, A. (2004). The Goan economy. Retrieved from http://www.india-seminar.com/2004/543/543\%20alban\%20couto.htm

Csikszentmihalyi, M. (1990). Flow: The psychology of optimal experience. New York, N.Y.: Harper and Row.

Dritsakis, N. (2004). Tourism as a long-run growth factor: An empirical investigation for Greece. Tourism Economics, 10(3), 305-316.

Fanon, F. (1967). Black skin, white masks. New York, N.Y.: Grove Press.

Fayissa, B., Nsiah, C., \& Tadasse, B. (2007). The impact of tourism on economic growth and development in Africa. Working Paper Series, Department of Economics and Finance, Middle Tennessee State University.

Fernandes, N. (2012). Taj Mahal foxtrot: The story of Bombay's jazz age. New Delhi: Lustre Press.

Gerson Da Cunha, J. (1894). A brief sketch of the Portuguese and their language in the east. Journal of the Asiatic Society of Bombay, 18, 168-191.

Goa Department of Tourism. (2001). Goa tourism master plan. Consultants' final report. Goa: Department of Tourism.

Hamilton, R. S. (1988). Creating a paradigm and research agenda for comparative studies of the worldwide dispersion of African people. Monograph No. 1, African Diaspora Research Project. East Lansing, MI: Michigan State University.

Kamat, N. (2007, September 24). Ensuring sustainability of Goa's tourism. The Navhind Times.

King, C. (1999). Views of difference: Different views of art. New Haven and London: Yale University Press. 
Krugman, P. (1979). Increasing returns, monopolistic competition, and international trade. Journal of International Economics, 9(4), 469-479.

Nkrumah, K. (1970). Consciencism: Philosophy and ideology for decolonization. New York, N.Y.: Monthly Review Press.

Noronha, F. (1997). Goa: Fighting the bane of tourism. Economic and Political Weekly, 32(51), 3253-3256.

Oh, C. (2005). The contributions of tourism development to economic growth in the Korean economy. Tourism Management, 26(1), 39-44.

Phaldesai, P. (2004). Kaleidoscopic Goa: A cultural atlas. Panaji, Goa: Vasantro Dempo Education \& Research Foundation.

Raikar, R. (2008, May 12). Migrants may number 3.25 lakhs in Goa. The Navhind Times.

Said, E. (1979). Orientalism. New York, N.Y.: Vintage Books.

Saldanha, A. (2002). Music tourism and factions of bodies in Goa. Tourist Studies, 2(1), 43-62.

Seligman, M. (2011). Flourish. New York, N.Y.: Simon \& Schuster.

Sen, A. (1999). Development as freedom. New York, N.Y.: Anchor Books/Random House.

Stigler, G., \& Becker, G. (1977). De gustibus non est disputandum. American Economic Review, 67(2), 76-90.

Swarbrooke, J., \& Horner, S. (1999). Consumer behavior in tourism. Oxford: Butterworth.

Swords, A., \& Mize, R. (2008). Beyond tourist gazes and performances: US consumption of land and labour in Puerto Rican and Mexican destinations. Latin American Perspectives, 35(2), 53-69.

Urry, J. (1990). The tourist gaze: Leisure and travel in contemporary societies. London: Sage Publications. 